DOI 10.37882/2223-2982.2020.05.12

\title{
ЭКОНОМИЧЕСКИЕ ЗАДАЧИ КАК СРЕДСТВО ПОВЫШЕНИЯ МАТЕМАТИЧЕСКОЙ ГРАМОТНОСТИ
}

\section{ECONOMIC PROBLEMS AS A MEANS OF IMPROVING MATHEMATICAL LITERACY \\ V. Kazarina \\ T. Fomina}

Summary: The introduction of the economic content problem in the state final certification is not accidental. Their solution contributes to a better assimilation of the content of the entire course of secondary school mathematics, to form a systematic, scientific worldview and allows the transfer of knowledge and skills in related disciplines, in particular in Economics.

Economic theory as a social science that studies the problem of choice in conditions of limited resources for maximum satisfaction of people's needs, is designed to explain events in economic life using models of reality, to reflect the real economy. That is why the main criterion for expert assessment of the correctness of the task on the unified state exam is the skill «construction and research of a mathematical model».

Keywords: mathematical literacy, school education, management risks, economic concepts.
Казарина Вера Викторовна

К.n.н., дочент, ГАУ ДПО «Институт развития образования Иркутской области»

vvkaz@yandex.ru

Фомина Татьяна Михайловна

старший методист, ГАУ ДПО «Институт развития образования Иркутской области»

Аннотация: Введение задачи экономического содержания в государственную итоговую аттестацию не случайно. Их решение способствует более качественному усвоению содержания всего курса математики средней школы, формировать системное, научное мировоззрение и позволяет осуществлять перенос полученных знаний и умений в смежные дисциплины, в частности в экономику.

Экономическая теория как общественная наука, изучающая проблему выбора в условиях ограниченности ресурсов для максимального удовлетворения потребностей людей, призвана объяснять происходящие события в экономической жизни с помощью моделей действительности, отражать в себе реальную экономику. Именно поэтому основным критерием для экспертной оценки правильности выполнения задания на ЕГЭ выбран навык «построения и исследования математической модели».

Ключевые слова: математическая грамотность, школьное обучение, риски управления, экономические понятия.

вой финансовый кризис заставил интересоваться экономикой даже тех, кому в обычные времена это не пришло бы в голову» [36]

Принцип учёта индивидуальных особенностей обучающихся при изучении экономических задач находит отражение и в критериях оценивания. Эксперты должны понимать, что «способов верного решения заданий этого типа никак не меньше, чем для привычных текстовых задач. Возможен и стиль, приближенный к высшей математике, и наивный подход, напоминающий арифметический способ решения текстовых задач, и метод использующий специфические для математической экономики понятия (целевая функция, симплекс-метод и т.п.)». Школьный учитель же должен показывать различные способы решения, опираясь на структуру мышления обучающихся.

\section{Разработанность вопроса}

Предпринимаются попытки систематизировать экономические задачи, предлагавшиеся на ЕГЭ по математике в разные годы, по темам и методам решения Ю.В. Садовничий [30; 31], И.В. Ященко и др.

Разработаны варианты, представлены решения от- 
дельных вариантов [15, ЕГэ 36 вар]

По такому же принципу построено изложение материала в большинстве пособий для подготовки и самоподготовки к ЕГЭ. В основном, формат изданий - тематические тренинги, которые содержат минимум теории - выдержан полностью, автор отмечает, что необходима личность учителя. Но понимают ли это учителя, ограничиваясь «прорешиванием» заданий, аналогичных ЕГЭ предыдущих лет зачастую за полгода до экзамена? Могут ли обучающиеся самостоятельно, без помощи наставника подготовиться к испытаниям и, что намного важнее, решать аналогичные задачи в жизни?

С целью изучения основ экономической теории разработаны учебники, изучение которые помогают учителю формировать у обучающихся старших классов целостные представления о сути экономических явлений, формировать основы экономической грамотности.

\section{Наработки педагогов}

Решение задачи несколькими способами, оформление задачи таблицей, рассматривая величин процесса кредитования, их взаимосвязь и взаимообусловленность (А.Н. Слепцова [33])

В профильных программах с целью освоения основных экономико-математических методов необходимо владение традиционным аппаратом математики и логики, изучаемом в школьных программах: дроби, проценты, уравнения, логические задачи. А эти знания у современных студентов не всегда сформированы. [1, С.6] В.А. Абчук, анализирую подготовленность студентов экономических специальностей, отмечает, что «когда дело доходит до расчётов, связанных с дробями или процентами, школьная эрудиция многих даёт осечку» [1, С.10].

В 2017-19 годах задание 17 представляло собой задачу на кредиты. Процент решивших задание из всех выпускников основного дня в Российской Федерации оказался в пределах статистики для решения подобных заданий: 1 балл получило 5,35\% от общего числа участников экзамена, 2 балла - 5,35\%, 3 балла - 17,16\%.

Основными ошибками явились неверное составление модели; вычислительные (арифметические); прекращение решения на промежуточном шаге, то есть без доведения ответа до числового значения; решение методом перебора без обоснования единственности; использование в решении без вывода формул для задач о кредитовании, отсутствующих в учебниках (решение имеет вид «формула - ответ»), что можно трактовать как отсутствие построения модели задачи (А.А. Прокофьев $[28 ; 29])$ По данным федеральной имеет наибольшее количество выходов на апелляцию.
В Иркутской области регулярно проводится анализ статистических данных о результатах единого государственного экзамена (ЕГЭ). В Иркутской области результаты по математике нельзя назвать стабильными. Например, в целом результаты ЕГЭ по математике профильного уровня в 2016 году были значительно лучше, чем в 2015 году: средний тестовый балл увеличился по сравнению с 2015 годом на 7,18. Однако, в 2018 произошел спад: средний балл по математике уменьшился на 2,22 по сравнению с 2016 годом и на 1,66 по сравнению с 2017 годом.

Все вышесказанное говорит о снижении качественных показателей результатов ЕГЭ по математике профильного уровня, по сравнению с 2016 и 2017 годами при незначительном увеличении доли участников, набравших балл не ниже минимального.

- По математике базового уровня средний балл в 2018 году увеличился по сравнению с 2016 годом на 0,2, а по сравнению с 2017 годом - на 0,06.

- Значительно (с 4,14 до 0,82) уменьшилась доля участников ЕГЭ по математике профильного уровня, получивших от 81 до 100 тестовых баллов.

- Доля участников ЕГЭ по математике профильного уровня, набравших балл ниже минимального, уменьшилась на 2,12 по сравнению с 2017 годом, а на ЕГЭ базового уровня доля участников, набравших балл ниже минимального, увеличилась на 0,5 .

В 2018 году по сравнению с 2017 годом участники экзамена основного дня в части заданий с развёрнутым ответом заметно лучше справились с заданиями 13 (19,4\% против $12,4 \%)$ и $15(14,5 \%$ против $6,4 \%)$, и заметно хуже - с заданием 17(1,1\% против 9,2\%). (С. 23).

- участники, набравшие более 80-ти баллов из задач с развернутым решением повышенного уровня хуже всего справились с заданиями 17, 18 и 19 (по каждому из этих заданий сумели набрать баллы лишь около половины учащихся этой группы).

- Одной из причин допущенных ошибок, видимо является то, что на уроках в одиннадцатом классе зачастую вместо планомерного изучения материала и проведения необходимых обоснований занимаются «натаскиванием» на типовые задачи ЕГЭ и типовые приёмы их решения. Это объясняет и то, что выпускники плохо справляются с задачами по темам, изучаемым в старших классах (свойства функций, задачи по стереометрии).

Кроме того, при решении, в частности, экономической задачи (задание 17) выпускники не вдумываются в смысл задания, а применяют готовые формулы, что приводит к тому, что решение оказывается недостаточно обоснованным или вообще неверным, из-за невнимательного прочтения условия и использования не тех 
формул. Учащиеся «тупеют» от большого количества различных формул и приёмов без их понимания. Навыки формальной логики отсутствуют у всё большего количества выпускников.

Не приступили к выполнению задания С-17 в 2018 году 8517 выпускников, что составляет 89,56\% от общего количества участников ЕГЭ в Иркутской области. Анализ выполнения этого задания показал, что выпускники 26 муниципальных образований (МО), что составляет 62\% всех МО Иркутской области, количество не приступавших к выполнению этого задания было еще больше. Из $10,44 \%$ приступивших решение данного задания на «0» баллов оценено у 10,07\%, на «1»- 0,13\%, «2»- 0,03\%. Полностью верно выполнили задание 0,21\% выпускников 2018 года.

В регионе проводятся регулярные семинары, мастерклассы, организуется освоение дополнительных профессиональных программ повышения квалификации учителей математики, на которых рассматриваются и вопросы методики решения текстовых задач с экономическим содержанием. В результате системной деятельности педагогов в 2019 году с заданиями профильного ЕГЭ по математике, проверяющими умение использовать знания по математике в практической деятельности и повседневной жизни, № 1 и № 2 базового уровня (выполнили верно соответственно 96\% и 98\% выпускников) и № 10 профильного уровня (69\%) участники экзамена справились лучше, чем с остальными заданиями. С заданием повышенного уровня № 17 справилось 5,5 \%. В 2019 году к заданию C-17 не приступало меньшее количество обучающихся, чем в предыдущие годы (7819 человек, 87,44\% от общего количества выпускников), произошло увеличение количества приступивших на 2,12\%. Повысилось и качество выполнения задания: снизилось до 8,51\% количество участников, получивших «0» баллов, полностью верно выполняют задание уже 3,21\% выпускников. Но данные результаты нельзя считать достаточными.

В 2019 году уже в 31 МО количество не приступивших к выполнению задания было больше, чем в целом по Иркутской области, причём из них в 24 МО (57\%) этот показатель ниже областного уже не первый год.

\section{Систематизашия ошибок}

А.А. Прокофьев отмечает, что многие участники экзамена действовали по аналогии с решениями подобных задач, представленными на различных сайтах или в пособиях для подготовки к ЕГЭ. Основной ошибкой при решении задач на кредиты и вклады можно считать отсутствие математической модели изучаемой ситуации. Это бывает в случае, если решение основывается на применении окончательной формулы, которой нет в официальных учебниках, без ее вывода, что недопустимо в соответствии с разделом 3, пункта 2 «Спецификации контрольных измерительных материалов для проведения в 2017 году единого государственного экзамена», т.е. используется модель без обоснования. Или решение основано на применении метода перебора без достаточных обоснований единственности решения задачи, то есть также отсутствует этап построения модели. [28; 29]

Особенностью является то, что для её решения необходимо знать небольшой объем теоретического материала, чаще всего только понятие процента. Вместе с тем, задача чаще всего вызывает затруднения у выпускников.

Причиной этому служат и объемные вычисления, и громоздкие формулировки текста, и другие причины. Мы считаем, что одной из причин является недостаточная работа по обучению школьников математическим методам решения экономических задач, так и учёт индивидуальных особенностей учащихся.

\section{Вицы экономических замач}

Классификация Ф.Ф. Лысенко: денежные расчеты, понятие процента, «экономические» задачи, Экономические задачи [19]

Ю.В. Садовничий классифицирует задачи по применяемым методам решения: предварительные задачи, формула сложных процентов, исследование функций и графические иллюстрации, задачи на оптимизацию, специфика целых чисел. Невозможность классифицировать какие-либо из задач он относит к категории «другие задачи» [30; 31]

Учителя классифицируют задачи по типам вопросов: нахождение ежегодной выплаты (транша), нахождение суммы кредита, задачи на вычисление процентной ставки, нахождение количества лет выплаты кредита, на оптимизацию и другие [33]

\section{Введение введения понятия \%}

Для успешного участия во Всероссийской олимпиаде школьников даже на муниципальном уровне необходимо владеть такими понятиями, как альтернативная стоимость, упущенная выгода, кривая производственных возможностей, спрос и предложение, рыночное равновесие и многими другими.

Экономические науки понимают под процентом (ссудным процентом) в обобщенном виде, по распространенным зарубежным представлениям, понимают плату за пользование заемными средствами, которая обычно выражается в виде ежегодной процентной ставки $[34 ; 35]$. насчитывают более 20 понятий процентов. 
Среди них накопленные и начисленные, номинальные и чистые и многие другие [34; 35]. В школьном курсе математики понятие процента вводится как сотая часть. В решении задач ЕГЭ - процент понимается как мировой экономике.

На элективных, факультативных курсах школьники знакомятся только с некоторыми из них - простыми и сложными.

С. 7. Начиная с 2015 года ЕГЭ по математике разделён на два уровня: базовый и профильный. Надо готовить на обоих уровнях. Задания с кратким ответом содержат краткие теоретические сведения, необходимые для успешного выполнения заданий, набор заданий, аналогичных встречающимся в экзаменационных работах. За заданием с решением приводят несколько примеров для самостоятельного выполнения. Задания для контроля

С. 11. Способ организации процесса обучения зависит от учителя. Могут решать задания на уроке по определённой теме или по различным темам. Можно использовать для ознакомления с методами решением заданий базового, повышенного и высокого уровня сложности, для организации диагностики и контроля (самоконтроля). Использовать целесообразно при самоподготовке.

\section{Аенежные расчёты}

\section{С. 22 Денежные расчёты.}

Часто приходится определять затраты на приобретение различных товаров. Например, зная, что цена за 1 м3 воды составляет 20 рублей 30 копеек, узнаем стоимость 150 м3 воды.

При решении приводит способ, который служит пропедевтикой понятия процент. При переводе копеек в рубли автор подробно комментирует т действия: «Переведём в рубли сумму 20 рублей 30 копеек. Копейка - это $\frac{1}{100}$ рубля, значит 30 копеек равны $\frac{30}{100}=0,3$ рую́яя. Отсюда 20 рублей 30 копеек = 20,3 рубля». После автором указывается алгоритм действия: «Теперь найдем произведение $150\left(\right.$ ( $\left.^{3}\right)$ и 20,3 (руб. за м³).» и делается вывод: «Значит,

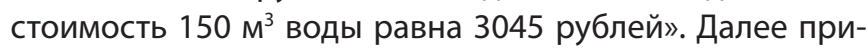
водятся задача, аналогичных для человека, владеющего методом их решения. Но на самом деле их решение сводится к выполнению более широких алгоритмов: найти, сколько сдачи должен получить покупатель, сравнить два расчёта на лечение и т.п. Из десяти предложенных для самостоятельного решения задач к трём приводятся решения в конце книги, содержащие вычисления, но не смысловую работу с величинами.

Аналогично рассматривается тема «Проценты». При- водится минимальное количество теоретического материала. Причём, пояснения не соотносятся с правилами, алгоритмами, которые проверяется на экзамене.

Например, в учебниках ...

Виленкин, Н.Я. Математика. 6 класс : учеб. для общеобразоват. Учреждений / Н.Я. Виленкин, В.И. Жохов, А.С. Чесноков, С.И. Шварцбурд. - 30-е изд., стер. - М. : Мнемозина, 2013. 288 с. : ил.

С. 79 в теме «Нахождение дроби от числа» решаются более сложные задачи. Даётся правило: «Чтобы найти дробь от числа, нужно умножить число на эту дробь». С позиции математики на основании переместительного закона запись «р\% от числа А - это $\frac{p .4}{100}$ С. 23 получается при выполнении этого правила. Методически обосновано, что необходимо напоминать обучающимся те законы и правила, которые они когда-то (шесть лет назад) изучали, учить мыслить, проводить аналогии, вспоминать, а не предлагать новые, более эффективные записи без опоры на имеющийся опыт. Согласно заложенным алгоритмам учителю необходимо напоминать учащимся правило и выполнять запись в виде « р\% от числа А - это $A * \frac{p}{100}$, дополняя её воспроизведением вслух правила не только на первых уроках повторения при подготовке к экзамену, но и в сложных задачах.

С этих позиций более успешно обобщается теория, если учащиеся вспоминают суть пропорции. Ю.В. Садовничий, вводя процент как сотую часть числа, говорит, что если число b составляет р\% от числа а, то верно следующее соотношение: $\frac{b}{a}=\frac{p}{100}$, где можно по двум известным величинам найти третью.

\section{Введение метода}

По данным анкетирования, из 111 учителей математики Иркутской области, осваивавших дополнительные профессиональные программы повышения квалификации в ГАУ ДПО «Институт развития образования Иркутской области», (78\%) имеют потребность в изучении методов решения задач с экономическим содержанием, затруднено.

Решение задач с экономическим содержанием вызывает интерес у педагогов, но по методике их решения представлено не так много материала в открытых источниках. во входной диагностики. более 20слушателей поскольку с одной стороны с другой - по данным анкетных данных показало большое желание разобраться в их решении на собственном опыте.

Решение подобных задач предполагает проверку следующих умений учащихся: 
- переходить от текста задачи к построению соответствующей математической модели;

- обращаться с целыми числами, то есть уметь использовать при решении задач элементы теории делимости целых чисел;

- производить действия со степенями с натуральным показателем;

- обращаться с процентами, сложными (банковскими) процентами и долями.

\section{Выво}

В дальнейшем планируется разработать систему экономических задач, ориентированная на различные подструктуры математического мышления (И.С. Якиманская, И.Я. Каплунович и др). Считаем, то опора на ведущую подструктуру математического мышления (топологическую, проективную, порядковую, метрическую и алгебраическую) значительно повышает эффективность усвоение различных методов решения экономических задач.

\section{ЛИТЕРАТУРА}

1. Абчук, В.А. Экономико-математические методы: Элементарная математика и логика. Методы исследования операций, СПб.: Союз, 1999. - 320 с.

2. Азарова, Л.А. Метод «стаканчиков» при решении задач на смеси и сплавы Инфоурок. Единый образовательный портал России Электронный ресурс https://infourok.ru/metod-stakanchikov-pri-reshenii-zadach-na-smesi-i-splavi-1571458.html

3. Алгебра. 7 класс : учеб. Для общеобразоват. Учреждений / А45 [Ю.Н. Макакрычев, Н.Г. Миндюк, К.И. Нешков, С.Б. Суворова]; под ред. С.А. Теляковского. - М. : Просвещение, 2013. - 256 с. : ил.

4. Алгебра. 9 класс : учеб. для общеобразоват. организаций / А45 [ Ю.Н. Макакрычев, Н.Г. Миндюк, К.И. Нешков, С.Б. Суворова]; под ред. С.А. Теляковского. - М. : Просвещение, 2014. - 271 с. : ил.

5. Алгебра и начала математического анализа. - 10-11 классы. А45. В 2 ч. Ч. 2. Задачник для учащихся общеобразовательных учреждений (базовый уровень) / [А.Г. Мордкович и др.] : под ред. А.Г. Мордковича. - 14-е изд., стер.- М.: Мнемозина, 2013. - 271 с.: ил.

6. Алешковский, И.А. Математика в экономике: экономико-математические задачи на проценты и доли: пособие для поступающих на экономический факультет МГУ им. Ломоносова. - 3-е изд., испр., перераб. - М.: МАКС Пресс, 2006. - 80 с.

7. Алешковский И.А., Картаев Ф.С. Математика в экономике. Экономико-математические задачи: от начального до олимпиадного уровня, Пособие для учащихся 10-11 профильных классов общеобразовательных учреждений и абитуриентов экономического факультета МГУ имени М.В. Ломоносова, 5-е издание, Издательство 000 «Макс Пресс», Москва 2009. - 361 с.

8. Виленкин, Н.Я. Математика. 6 класс : учеб. для общеобразоват. Учреждений / Н.Я. Виленкин, В.И. Жохов, А.С. Чесноков, С.И. Шварцбурд. - 30-е изд., стер. - М. : Мнемозина, 2013. 288 с. : ил.

9. Гаер, М.А. Результаты государственной итоговой аттестации в форме единого государственного экзамена по математике профильного уровня в Иркутской области в 2019 году. Методические рекомендации / М. А. Гаер, к.т.н., Е.С. Лапшина, к.ф.-м.Н., С.Н. Марков, к.ф.-м.н. - Иркутск: ГАУ ДПО ИРО 2019,46 с.

10. Гальперин П.Я. Психология как объективная наука Под рел. А.И. Подольского. - М.: мышления и учение о поэтапном формировании умственных действий. — Исследования мышления в советской психологии. М., 1966 // Введение в психологию. М., 1976.

11. Гатауллина, Г.А. Решение экономических задач с помощью таблицы / Г.А. Гатауллина [Электронный ресурс] г. Вятнские Поляны, Кировская область, 2019. - Режим доступа: https://nsportal.ru/shkola/algebra/library/2019/08/14/reshenie-ekonomicheskih-zadach-s-pomoshchyu-tablitsy-v-ege , свободный. Дата обращения: 31.01 .2020 г.

12. Гусельникова, И.В. Сборник игр, заданий и ответов по экономике / Ирина Викторовна Гусельникова. Методическая разработка к учебному курсу первого года обучения дополнительной программы «Экономика домашнего хозяйства». Тольятти, 2016. https://infourok.ru/sbornik-igr-i-zadaniy-poekonomike-1331821.html

13. Демонстрационный вариант контрольных измерительных вариантов

14. https://4ege.ru/matematika/58234-demoversii-ege-2020-po-matematike.html

15. ЕГЭ. Математика. Профильный уровень: типовые ЕЗ1 экзаменационные варианты: 36 вариантов / под ред. И.В. Ященко. - М.: Национальное образование, 2019. -256 c.

16. Каплунович, И.Я.. Пять подструктур математического мышления: как их выявить и использовать в преподавании / И.Я. Каплунович, Т.А. Петухова // Математика в школе. 1998. № 5. С. $45-48$.

17. Критерии проверки и оценка решения заданий вариантов КИМ ЕГЭ-2016 [Электронный ресурс] / https://4ege.ru/matematika/52133-kriterii-ocenivaniyazadaniy-13-19.html, свободный. Дата обращения: 10.03 .2020 г.

18. Коняхина, Л.Н. Учимся решать задачи по экономике: Учебное пособие / Л.Н. Коняхина. - Курган: Изд-во Курганского гос. ун-та, 2009. - 118 с.

19. Математика. ЕГЭ-2017. Тематический тренинг. 10-11 классы: учебно-методическое пособие / Под редакцией Ф.Ф. Лысенко, С.О. Иванова. - Ростов-наДону: Легион, 2016. - 432 с. - (ЕГЭ)

20. Методический анализ результатов единого государственного экзамена по математике в Иркутской области в 2018 году. Методические рекомендации / https://new.iro38.ru/gosudarstvennaja-itogovaja-attestacija

21. Мерзляк, А.Г. Математика : 5 класс : учебник для учащихся общеобразовательных организаций / А.Г. Мерзляк, В.Б. Полонский, М.С. Якир. - М. : ВентанаГраф, 2014. -304 с. : ил. 
22. Мордкович, А.Г. Алгебра. 8 класс. В 2 ч. Ч. 1 Учебник для учащихся общеобразовательных учреждений / А.Г. Мордкович. - 12-е изд. Стер. - М. : Мнемозина, 2-10. - 215 с. : ил.

23. Основы экономической теории. Учебник для 10-11 классов. Книга 1. (под ред. С.И. Иванова) / С.И. Иванов. 7-е изд. - М. : Вита пресс, 2006. Кн. 1. - 336 с.

24. Плакатина 0.И. Специальная методика преподавания математике в средней школе: Учеб. пособие по теории и методике обучения математике для студентов педагогических вузов специальности - математика / 0.И. Плакатина. - Иркутск, 2004. - 268 с.

25. Практикум по решению экономических задач [Электронный ресурс] : методическое пособие для учителей общеобразовательных организаций / А.А. Егорова, Е.В. Кузнецова, Д.И. Никитин. - Челябинск : ЧИППКРО, 2017. - 52 с.

26. Позднякова, П. Проект «50 экономических задач» / П. Позднякова https://4ege.ru/matematika/56745-50-ekonomicheskih-zadach.html

27. Пойа, Д. Как решать задачу? / Д. Пойа - Ловов. Журнал «Квантор». 1991. - 216 с.

28. Прокофьев, А.А. Рекомендации по подготовке к выполнению финансово-экономических задач ЕГЭ повышенного уровня [Электронный ресурс] / А.А. Прокофьев. - Материалы межрегиональной конференции учителей математики «Повышение качества основного и дополнительного математического образования в рамках Концепции развития математического образования в Российской Федерации». - М. : МГУ им. М.В. Ломоносова, 26 ноября 2017 года. Режим доступа: https://alexlarin.net/ege/2018/ap17.pdf, свободный. Дата обращения: 31.01.2020 г.

29. Прокофьев, А.А. Математика. ЕГЭ. Социально-экономически задачи (типовое задание 17): учебно-методическое пособие / А.А. Прокофьев, А.Г. Корянов. - 2-е изд., перераб. - Ростов-на Дону, Легион, 2018. - 160 с.

30. Садовничий, Ю.В. ЕГЭ 2019. 100 баллов. Математика. Профильный уровень. Экономические задачи / Ю.В. Садовничий. - М.: Экзамен, 2019. - 94 с.

31. Садовничий, Ю.В. ЕГЭ, Математика. Профильный уровень. Задания с развернутым ответом / Ю.В. Садовничий. - М.: Издательство «Экзамен», 2019. 654 с. (Серия «ЕГЭ. Банк заданий»).

32. Сборник задач I и II открытых чемпионатов школ по экономике, под ред. Ф. Картаева и 0. Клачковой. М.: Альпина Паблишер, 2013. [Электронный ресурс] Режим доступа: https://docplayer.ru/30587500-Sbornik-zadach-i-i-ii-otkrytyh-chempionatov-shkol-po-ekonomike.html (Дата 0бращения: 12.10.2019 г.).

33. Слепцова А.Н. Экономические задачи в заданиях ЕНГЭ по математике. Сборник экономических задач и задач на оптимизацию по математике ГЭлектронный ресурс ]/ А.Н. Слепцова. - Чурапча, 2017. - 23 с. Режим доступа: https://yagubov.ru/_Id/99/9960_9960Z_Yagubov.R.pdf, свободный. Дата обращения: 04.02.2020 r.

34. Словарь-справочник: экономика, внешняя торговля, выставки / авт.-сост. П.А. Кошель; под общ. ред. В.Л. Малькевича. - М.: 0-во сохранения лит. наследия, 2012. - 344 с.: ил. 5.

35. Словарь финансово-экономических терминов / А. В. Шаркова, А. А. Килячков, Е. В. Маркина и др.; под общ. ред. д. э. н., проф. М. А. Эскиндарова. [Текст] - М.: Издательско-торговая корпорация «Дашков и К», 2015. - 1168 с.

36. Сонин, К.И. Уроки экономики [Электронный ресурс] / К.И. Сонин. - М.: «Юнайтед-Пресс», 2011. - 300 c. Режим доступа: https://www.rulit.me/books/soninru-urokiekonomiki-read-217276-1.html, свободный. (Дата обращения: 07.02.2020 г.).

37. Толстой, Л.Н. Арифметика. / Л.Н. Толстой. В двух частях. С указаниями для преподающего в конце книги. Типо-литография Т-ва И.Н. КУШНЕРЕВ. - Москва $-1913 .-159$ c.

38. Федеральный государственный образовательный стандарт высшего профессионального образования по направлению подготовки 080100 Экономика (квалификация (степень) «Бакалавр»). Приказ Министерства образования и науки Российской Федерации от 21 декабря 2009 г. № 747 (в ред. Приказа Минобрнауки РФ от 31.05.2011 № 1975) http://fgosvo.ru/uploadfiles/fgos/8/20111115140416.pdf

39. Фридман, Л.М. Как научиться решать задачи / Л.М. Фридман. - М.: Московский психолого-социальный институт: Воронеж: Издательство НПО «МОДЭК», 1999. - 240 с. (Серия «Библиотека педагога-практика»).

40. Фридман, Л.М. Теоретические основы методики обучения математике: Пособие для учителей, методистов и педагогических высших учебных заведений / Л.М. Фридман. - М.: Московский психолого-социальный институт: Флинта, 1998. - 224 с.

41. Шестаков, С.А. ЕГЭ-2020. Математика. Задачи с экономическим содержанием. Задача 17 (профильный уровень). ФГОС. - М.: МЦНМ0, 2020. - 208 с.

(c) Казарина Вера Викторовна (vvkaz@yandex.ru), Фомина Татьяна Михайловна.

Журнал «Современная наука: актуальные проблемы теории и практики» 